\title{
Concentration photovoltaic optical system irradiance distribution measurements and its effect on multi-junction solar cells
}

\author{
Rebeca Herrero*, Marta Victoria, César Domínguez, Stephen Askins, Ignacio Antón \\ and Gabriel Sala \\ Instituto de Energía Solar, Universidad Politécnica de Madrid, Madrid, Spain
}

\begin{abstract}
This paper proposes an indoor procedure based on charge-coupled device camera measurements to characterize the non-uniform light pattems produced by optical systems used in concentration photovoltaic (CPV) systems. These irradiance patterns are reproduced on CPV solar cells for their characterization at concentrated irradiances by using a concentrator cell tester and placing high-resolution masks over the cells. Measured losses based on the masks method are compared with losses in concentrator optical systems measured by using the Helios 3198 solar simulator for CPV modules.
\end{abstract}

\section{KEYWORDS}

concentration photovoltaic systems; instrumentation, measurement, and metrology; CCD; multi-junction cell; irradiance profile

* Correspondence

Rebeca Hertero, Instituto de Energía Solar, Universidad Politécnica de Madrid, Madrid, Spain.

E-mail: rebeca.herreromies-def.upm.es

\section{INTRODUCTION}

In concentration photovoltaic (CPV) systems, low-cost optical elements concentrate light onto high-efficiency solar cells, with the goal of producing a cost-effective solution for solar energy production. These optical systems must be evaluated in terms of optical efficiency. angular transmission, and irradiance distribution on the solar cell, among other things [1]. An important concern in optical designs for CPV systems is the non-uniformity of the irradiance distribution on the cell. which can cause loss of efficiency due to an increase in the effective series resistance. Tunnel diodes within the struchure of multi-junction (MJ) cells commonly used in CPV also impose a limitation on maximum local irradiance over the cell [2]. In addition. depending on spectral differences on light protìle distributions caused by refractive optics over top, middle, and bottom sub-cells, the MJ cell efficiency could decrease due to current mismalch between junctions [3]. As a result of this concern, many CPV optical systems are designed to produce uniform irradiance distribution on the cell by means of using a kaleidoscopic stage or Köhler integration [4]. For a given concentration ratio and acceptance angle specification, the uniform flux condition increases the number and complexity of the optical surfaces and could increase cost.

This paper seeks to characterize the electrical loss caused by non-uniform irradiance profiles in order to reveal the impact of the cell performance degradation on operation. compared with uniform light pattern on the cell. This information should allow CPV system designers to choose an optimum solution in the trade-off between cost, complexity, and illumination uniformity.

In the past, the effects of having non-uniform light distribution on CPV systems have been evaluated by simulations based on distributed circuit models [5]. Experimental results have been obtained by measuring the $1-V$ curve of an $\mathrm{MJ}$ solar cell under localized high flux intensity (10000 times the standard solar irradiance) applied to small size MJ cells in which contribution of contact metallization to series resistance is negligible [6] and also with the objective of determining the tunnel diode limit [7]. 
Simulations provide only good results if accurate data for the distributed model of the cell are available and the irradiance profiles over the cell are known. The irradiance profile depends not only on the optical design but also on optics manufacturing process. If the bulk and surface scattering of optics (which are very dependent on material and manufacturing process) are not accurately modeled, the irradiance profiles obtained by ray tracing simulations are much less uniform than actual profiles produced by manufactured optics. Therefore, a characterization tool is needed to determine the true irradiance profiles produced on the cell by CPV optics and the impact of non-uniform irradiance on MJ cell electrical performance.

In this paper, a method is presented to firstly characterize the irradiance profiles produced by CPV optics that may consist of one or several stages and secondly to reproduce synthetically these non-uniform irradiance patterns on the cell. By using a concentrator cell tester and a set of masks to cover the cell, non-uniform irradiance distributions are reproduced while $I-V$ curves are measured. The final objective is to evaluate fill factor $(F F)$ losses for an MJ solar cell due to non-uniform light distributions that replicate real optical system light distributions. The $I-V$ curves for several optical systems are obtained by using the collimated light of the Helios 3198 (Soldaduras Avanzadas S.L. Puertollano, Spain) solar simulator [8]. In order to validate the mask method, the FF losses gathered from both methods (CPV solar simulator and masks) are compared (Figure 1). The mask method should provide useful feedback to optical designers and allow them to avoid over-constraining optical design by over-valuing uniformity.

\section{CHARACTERIZATION OF IRRADIANCE PATTERNS PRODUCED BY CONCENTRATION PHOTOVOLTAIC OPTICS}

The majority of point-focus concentrator systems that use MJ solar cells consist of an arrangement based on a primary optical element (POE) such as Fresnel lens and a secondary optical element (SOE) whose purpose is to improve the acceptance angle, and thus the angular tolerance, and, in some cases, to homogenize the irradiance distribution over the solar cell. Depending on the design of the concentrator optical system and more specifically the SOE performance, the light pattern over the solar cell will show spatial and spectral non-uniformities $[9,10]$.

The experimental set-up used to capture the irradiance profiles at the exit of the CPV optical system is shown in Figure 2. The illumination system of the Helios 3198 solar simulator for CPV modules has been used in order to provide a collimated light beam similar to the sun. The illumination is based on a Xenon flash lamp and a large-area parabolic reflector ( $2 \mathrm{~m}$ in diameter) that converts divergent light beams coming from its focus into collimated ones. Thus, the input aperture of the POE is illuminated uniformly by a light source of similar angular distribution and spectrum to the sun. In the case of refractive optics, chromatic aberration produces distinct irradiance distributions for each wavelength. Therefore, the spectrum distribution of the used light must be similar to a reference solar spectrum. The solar simulator provides a light spectrum equivalent to the AM1.5D standard

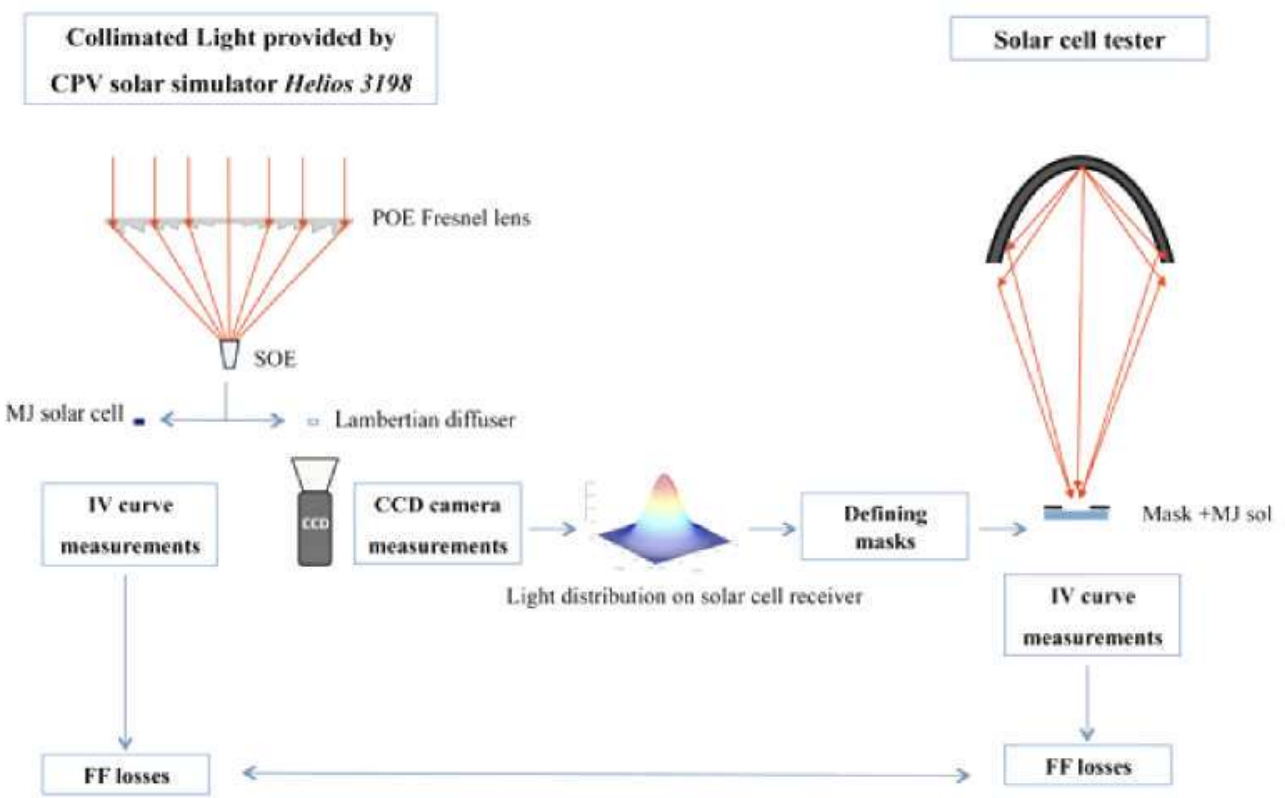

Figure 1. Diagram that summarizes measurements carried out in Helios 3198 concentration photovoltaic (CPV) module solar simulator and a mult-junction (MJ) cell tester during this research. CCD, charge-coupled device; FF, fill factor; POE, primary optical element; SOE, secondary optical element. 


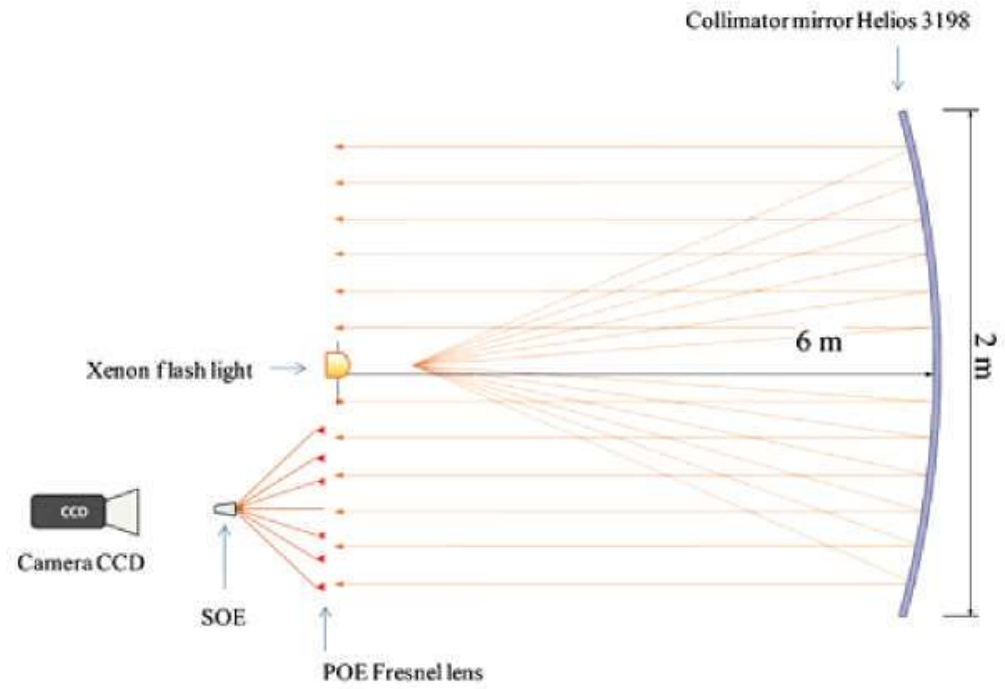

Figure 2. Measurement set-up used to capture light distributions caused by concentrator optical systems on the solar cell. CCD, charge-coupled device; POE, primary optical element; SOE, secondary optical element.

ASTM G173 used as reference in CPV characterization measurements [11].

The irradiance profile across the cell can be captured experimentally with a charge-coupled device (CCD) camera if the solar cell is removed and replaced by a quasi-Lambertian diffuser. In the case of systems with reflective SOEs or systems that lack an SOE entirely, a very thin sheet of treated glass is used. For dielectric secondaries, the exit facet of the SOE itself is treated so that it acts as the diffuser. When the camera is placed directly behind the concentrator and focused onto the exit facet of the SOE, the captured image is a representation of the irradiance profile created by the optical system on the solar cell plane.

Special care should be taken with very compact optical systems using dielectric SOEs, because total internal reflection could occur at the exit facet of the SOE for oblique rays, when removing the coupling to the solar cell (the refractive index of the cell is higher than the one of the air, $n_{\text {cell }}>n_{\text {air }}$ ). If these oblique rays do not exit the SOE back surface, the irradiance pattern is altered, and therefore the recorded image does not represent the irradiance reaching the solar cell.

The numerical aperture $(N A)$ at the exit of the SOE may be defined as

$$
N A=n \cdot \sin (\theta)
$$

where $n$ is the SOE index of refraction, and $\theta$ is the halfangle of the maximum cone of light that reaches the SOE back surface. For all the CPV optical systems analyzed in this paper, the NA of the beam at the exit of the SOE is lower than 1. This condition guarantees that all oblique rays are transmitted from the SOE exit facet to the air without being internally reflected. If $N A$ at the cell surface for a given system is higher than 1 , the surface treatment of the exit facet is a critical issue to prevent total internal reflection and correctly measure the uniformity of the light.

The CCD camera is equipped with a silicon CCD sensor, whose ultraviolet-enhanced spectral response covers from 400 up to $1050 \mathrm{~nm}$ wavelengths. By using a cold mirror and heat absorbing glass as long-pass and short-pass filters, respectively, the wavelength bands related to top and middle sub-cells can be split and measured individually. In Figure 3, the spectral response of the CCD sensor with filters is compared with common top and middle sub-cells.

However, the main concern in this study is the characterization of the non-uniform light patterns to be later reproduced by means of masks at indoor characterization of cell receivers. This approach does not enable the reproduction of different patterns for each sub-cell. For that reason, the light patterns are measured for the whole spectral range limited by the CCD spectral response, which completely covers the spectral ranges of top and middle, as well as part of the bottom range. The fact that the $\mathrm{CCD}$ response does not cover the entire bottom sub-cell spectral range is not important for two reasons. Firstly, dispersion for typical optical materials is very low for higher wavelengths. Thus, light distribution on the cell used by the bottom sub-cell is almost equal to the light distribution used by the middle sub-cell. Secondly, current MJ solar cell has an excess of bottom photogenerated current being either top limited or middle limited. Therefore, it is natural to focus our experiments on the behavior of the top and middle sub-cells.

In order to represent the measured irradiance pattern caused by the optics over the cell by using a onedimensional curve, the average light profile is defined and calculated from the captured CCD image as

$$
I_{\mathrm{P}}(\rho)=\frac{1}{2 \pi \rho} \sum_{\varphi=0}^{\varphi=2 \pi} Z(\rho, \varphi)
$$




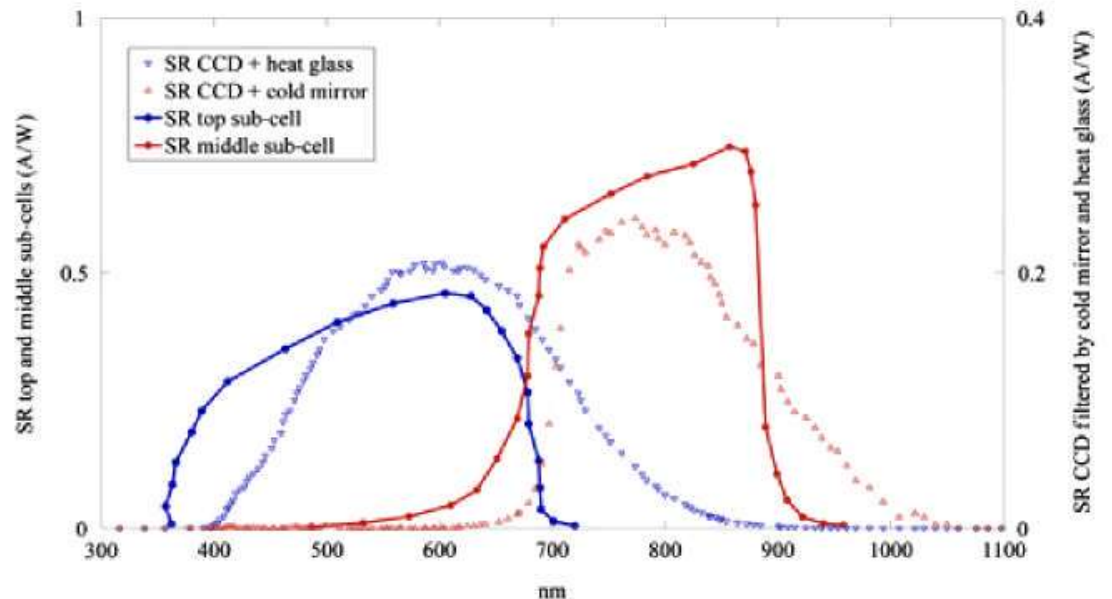

Figure 3. Spectral response (SR) of top and middle sub-cells compared with the spectral response of the charge-coupled device (CCD) sensor with filters, used to measure top and middle irradiance distributions.

where $Z$ is the irradiance pattern measured by the CCD camera and $(\rho, \varphi)$ the cylindrical coordinates.

An issue to be considered is that light profiles caused by concentrating optics depend directly on the angular distribution of the light source impinging the POE. As a consequence, irradiance profiles are slightly different with the sun disc or the toroidal Xenon bulb used in the solar simulator, even though the angular extensions of both sources are similar. The light profile related to a Fresnel lens illuminated by a toroidal lamp has the maximum shifted (see Figure 4), because the dark area of the center of the bulb causes an irradiance drop also in the center of the profile. On the other hand, a typical irradiance profile produced by a disc source like the sun provides the maximum irradiance at the center of the light profile, its shape being more Gaussian.

In Figure 4, the normalized average light profile caused by a common POE as a Fresnel lens is presented. The
Fresnel lens has a $25 \times 25 \mathrm{~cm}^{2}$ area and a $277 \mathrm{~mm}$ focal distance, and it is illuminated by a Xenon flash lamp.

\section{I-VCURVES OF MULTI-JUNCTION SOLAR CELLS UNDER NON-UNIFORM LIGHT PROFILES: MASK METHOD}

To compare different profiles, the peak-to-average ratio (PAR), or the ratio of the peak irradiance to the average irradiance of a given distribution, is defined as the representative parameter. To reproduce different profiles distributions over the cell, masks have been printed on transparent acetate film using a high-resolution photoplotter similar to those used in photolithography [12]. When a masked cell is illuminated with uniform irradiance, the mask provides a variable shading value across the cell surface, such that the

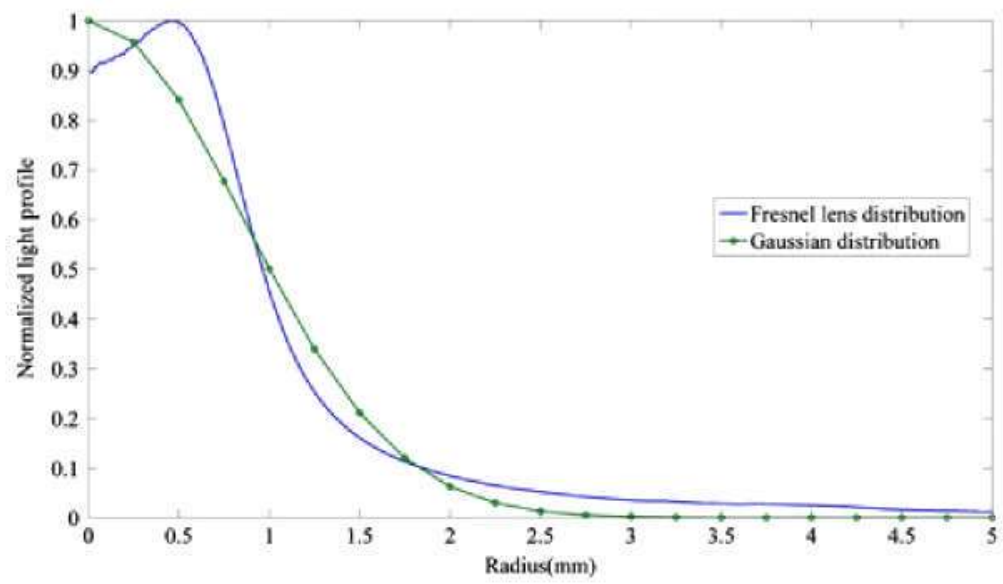

Figure 4. Normalized irradiance profile related to a Gaussian distribution (sigma $=0.85 \mathrm{~mm}$ ) and normalized irradiance profile caused by a Fresnel lens (when the optics is illuminated with Helios 3198 solar simulator) measured by using a charge-coupled device camera (considering wavelengths from 400 to $1050 \mathrm{~nm}$ ). 

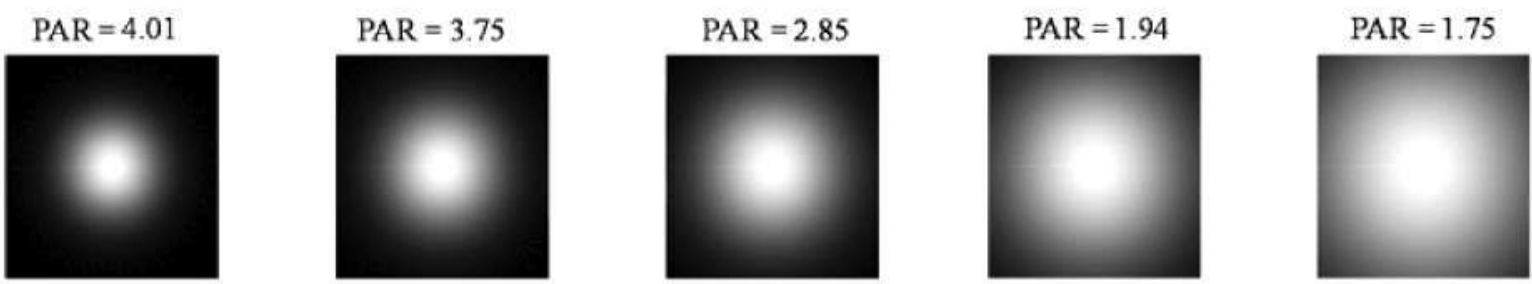

Figure 5. Examples of masks used to reproduce non-uniform light pattems on the solar cells $\left(1 \times 1 \mathrm{~cm}^{2}\right)$ and their relative peak-to-average ratio (PAR).

synthetic profile of the light transmitted is similar to that produced by a CPV optical system. Figure 5 shows examples of manufactured masks along with the corresponding PAR of each one (for $1 \times 1 \mathrm{~cm}^{2}$ solar cells). These masks can be used for testing the cells in the factory in more realistic optical and thermal conditions, in order to sort the cells if it is required.

Although any profile shape can be reproduced by masks, for the sake of simplicity only a family of masks providing Gaussian irradiance profiles are compared in this study. Most irradiance patterns produced by CPV optics systems aligned to the source produce an irradiance maximum at the center of the cell, with decreasing irradiance towards the edges. In the case of conventional CPV imaging optics illuminated by the sun disc, this decay is well approximated by a Gaussian curve [13]. Non-imaging optics designs providing nearuniform irradiance profiles (i.e., Köhler integration) can be related to a Gaussian profile with a much larger standard deviation than the size of the cell.

This approach produces a family of Gaussian curves that can be considered a calibration scale for the effects of the non-uniformity on concentrator cells. Even if the shape of this decay is not exactly Gaussian, we will show that this approximation accurately reproduces the losses of efficiency of the true profile.
To evaluate relative losses on efficiency and $F F$ due to real non-uniform light patterns, $I-V$ curves of MJ solar cells (masked and uniformly illuminated) have been obtained [14]. The $I-V$ curve measurements are carried out using a pulsed solar simulator for solar cells developed at the Instituto de Energía Solar-Universidad Politécnica de Madrid which is based on a Xenon flash lamp that provides an adjustable irradiance of up to 1000 suns (1 sun corresponds to $900 \mathrm{~W} / \mathrm{m}^{2}$, AM1.5D ASTM G173) and a uniformilluminated area at the receiver plane $(2 \%)$. The Xenon flash lamp is triggered to illuminate the receiver, whereas the solar cell is biased at several voltage values. The cell assemblies are attached to a temperature-controlled plate.

An MJ cell's performance is very sensitive to spectrum because MJ cells are a series-connected stack of two or more sub-cells, each sub-cell generating current in response to the light of different spectral bands. The spectrum of the light arriving at the device is controlled by means of component solar cells (also known as "isotypes") that have been characterized under the reference spectrum AM1.5D ASTM G173 [11]. Because absorption in the pseudo-transparent areas of the acetate mask may cause a change in the spectrum of the light the cells are exposed to, these isotype cells are also covered by an acetate film with no mask printed on it, so that they are subjected to

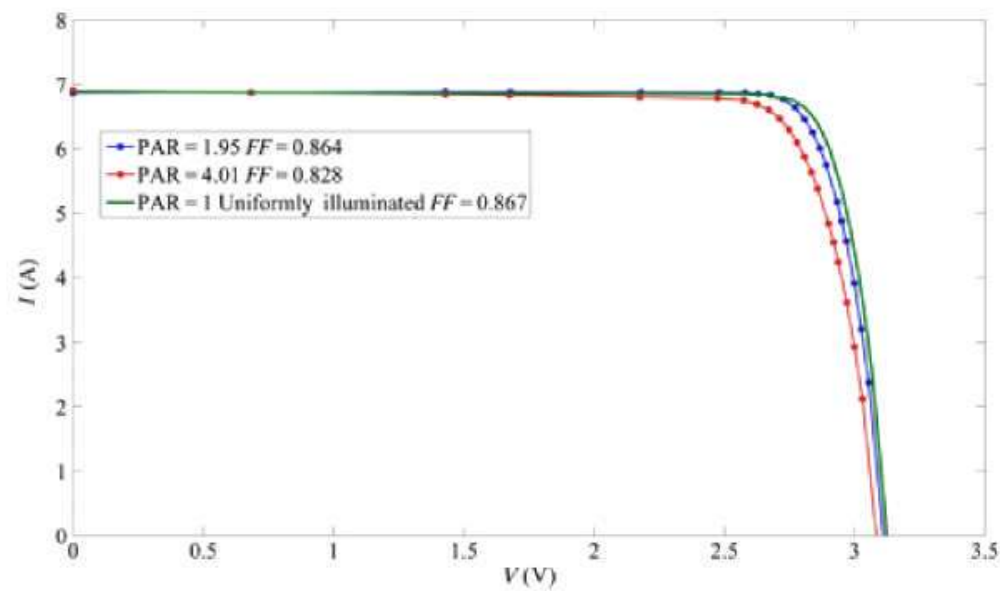

Figure 6. $L V$ curves related to multi-junction (MJ) solar cell uniformly illuminated versus an MJ solar cell covered with masks (peakto-average ratio (PAR) of 1.95 and 4.01 ) under $A M 1.5 D$ and 500 suns effective concentration (1 sun equals to $900 \mathrm{~W} / \mathrm{m}^{2}$ ). FF, fill factor. 

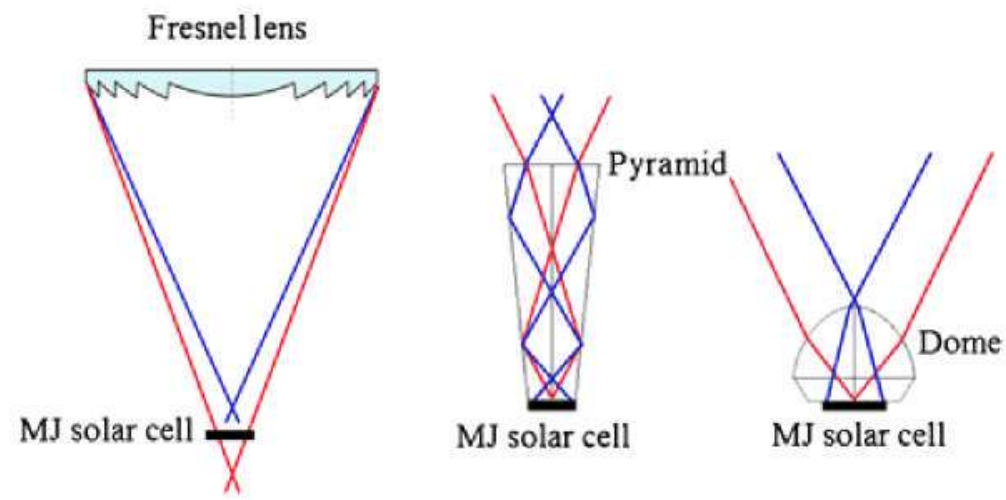

Figure 7. The optical systems studied in this paper consist of a Fresnel lens and different secondary optical elements (SOEs): homogenizer prism, dome, and no secondary optics. MJ, multi-junction.

the same spectrum as the MJ solar cell under test. Using these sensors, the cell tester illumination was adjusted to provide an AM1.5D equivalent spectrum for each mask tested. This equivalent spectrum provides the same current ratio of the sub-cells to the ratio obtained for the reference spectrum AM1.5D ASTM G173. In addition, the thermal plate was used to maintain cell temperature at $25^{\circ} \mathrm{C}$ to avoid effects unrelated to non-uniform illumination [15]. In order to ensure the cell is measured under the same effective concentration for all tests, the total irradiance was adjusted such that photogenerated current remained constant regardless of the mask used. In other words, for masks with high shading factors, the irradiance produced by the simulator was increased (maintaining spectral distribution) to compensate. In this way, measurement conditions were the same in all tests with the exception of the irradiance distribution on the cell.

Multi-junction photovoltaic cells used under concentrated light have large currents and consequently losses due to series resistance must be considered. The effects on solar cell performance derived from a non-uniform irradiance profile are distributed throughout the device, with the metal grid, emitter, contacts, and bulk region constituting the main sources of resistance [16]. For a Gaussian light profile, non-uniform illumination causes a drop in both opencircuit voltage and efficiency compared with a uniformly illuminated cell. As shown in Figure 6, an increase in non-uniformity decreases the fill factor. This is mainly due to an increase in series resistance losses and translates into a decrease in solar cell efficiency in operation.

\section{ASSESSMENT AND VALIDATION OF THE MASK METHOD}

The electrical characterization of several CPV optical systems was performed by the CPV solar simulator in order to validate the mask-based method.

By using the Helios 3198 illumination system, the irradiance profile of each optical system has been captured over the entire CCD spectral range. The PAR value for these experimental profiles was calculated, allowing each system to

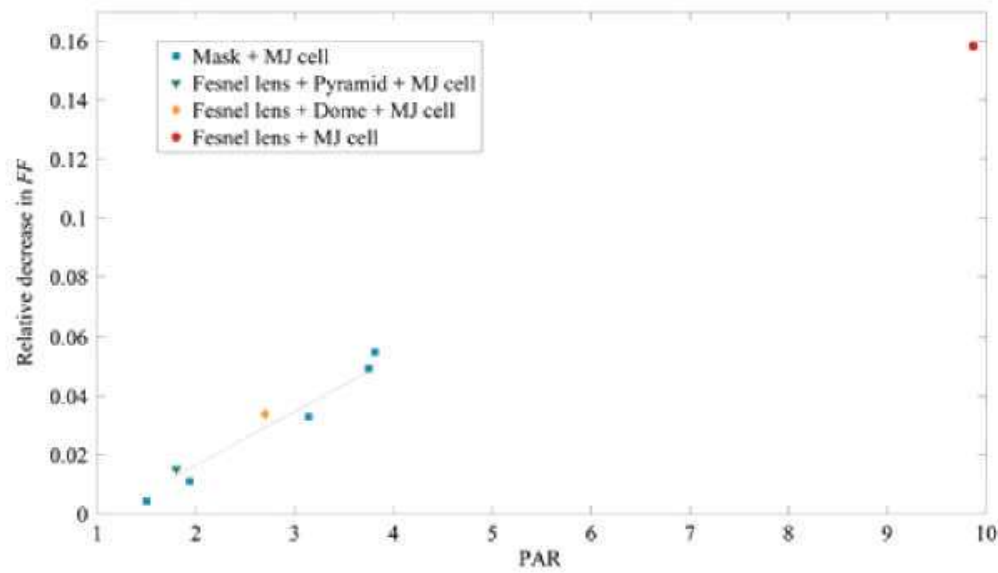

Figure 8. Percent variation of fill factor (FF): mask-based method (solar simulator for high concentration photovoltaic (HCPV) cells) versus optical system and cell measurements (solar simulator for HCPV modules). PAR, peak-to-average ratio; MJ, multi-junction. 
be assigned a comesponding Gaussian distribution mask with the same PAR. Then an MJ cell is mounted at the exit of the SOE and FF losses caused by non-uniform profiles are measured with Helios 3198. This was performed for several CPV optical systems (at $900 \mathrm{~W} / \mathrm{m}^{2}$ and equivalent AM1.5D at the aperture area of the Fresnel lenses) and compared with the results obtained by the mask method for the same irradiance level and spectrum.

The optical system configurations studied in this paper consist of a square acrylic Fresnel lens and different SOEs: homogenizer prism of glass [17]. dome-shaped integrator [18] of silicone rubber. and no secondary optics (see Figure 7). In this last case, a flat diffuser placed at the focus is used to capture the irradiance profile.

The decrease in $F F$ due to non-uniform imadiance illumination of the optical systems is defined as the variation of $F F$ related to a given irradiance profile compared with the $F F$ obtained with uniform illumination. In Figure 8, the $F F$ variations for real optical systems (measured with the Helios 3198 CPV solar simulator) are compared with FF variations obtained using the mask-based method (measured in the high concentration cell simulator).

As can be seen in Figure 8, the relationship between $F F$ and PAR measured in real optics is consistent with the relationship produced using the mask experiments with Gaussian profiles.

Nevertheless, variations on $F F$ measured for optic systems are slightly different due to several factors related to spectrum. When measuring the optical systems at the Helios 3198 CPV module solar simulator, the spectrum at the entrance of the optical system is equivalent to AM1.5D. However, because of the spectral response of the optics, the spectrum arriving at the cell cannot be considered equivalent to AM1.5D. This is a common issue in CPV module performance, because spectral variations at the entrance of the module produce different cument matching between top. middle. and bottom sub-cells due to the spectral mismatch and therefore different CPV module electrical performance [19.20]. The cell performance characterization with the mask method does not consider changes on spectrum due to optics, but it reproduces iradiance profiles of CPV systems without using optics for the cell test.

\section{CONCLUSIONS}

A mask-based method to produce non-uniform Gaussian irradiance profiles on CPV cells has been assessed for indoor characterization of MJ solar cells under concentrated light. The $I-V$ curves obtained with the masked cells under concentrated light have been compared with $I-V$ curves of CPV units that include the optical system and the cell receiver. The merit parameter PAR has been used to define a light profile pattern, so the curves of both methods have been compared for the same PAR, providing very consistent results.
When used to obtain efficiency losses due to non-uniform inadiance caused by a particular optical system. the mask method provides values close to those observed under real operating conditions for the optical system and solar cell. This method will allow the performance of a given concentrator cell for a wide range of PAR values to be experimentally determined without the need to physically consinuct oplical systems that create these irradiance profiles.

To carry out this work, it was also necessary to characterize the irradiance patterns produced by typical CPV optical systems. A method to measure these irradiance patterns was demonstrated.

\section{ACKNOWLEDGEMENTS}

This work has been partially supported by the Spanish Ministry MCEI under Consolider Ingenjo 2010 Program, Project GENESIS-FV (CSD20006-0004). and by the Community of Madrid under Project Numancia-2 (S2009/ENE-1477). Rebeca Herrero is thankful to the Spanish Ministerio de Educación for her FPU grant.

\section{REFERENCES}

1. Antón I, Pachón D. Sala G. Characterization of optical collectors for concentration photovoltaic applications. Progress in Photovoltaic: Research and Applications 2003: 11: 387-405.

2. Guter W, Bett AW. $I-V$ characterization of tunnel diodes and multi-junction solar cell. IEEE Transactions on Electron Devices 2006; 53(9): 2216-2222.

3. James LW. Effects of concentrator chromatic aberration on multi-junction cells. Proceedings of the IEEE First World Conference on Photovoltaic Energy Conversion, Waikoloa. HI. 1994.

4. Hernández M, Cvelkovic A, Benítez P. Miñano JC. High-performance Köhler concentrators with uniform irradiance on solar cell. In Nonimaging Optics and Efficient Illumination Systems V (Proceedings of the SPIE), Winston R, Koshel RJ (eds). SPIE: Bellingham, WA, 2008.

5. Garcia I. Algora C, Rey-Stolle I, Galiana B. Study of non-uniform light profiles on high concentration III-V solar cells using quasi-3D distributed models. Proceedings of the 33rd IEEE Photovoltaic Specialists Conference, San Diego, CA 2008.

6. Katz EA, Gordon JM, Feuermann D. Effects of ultrahigh flux and intensity distribution in multi-junction solar cells. Progress in Photovoltaic: Research and Applications 2006; 14: 297-303.

7. Braun A, Hirsch B. Katz EA. Gordon JM, Guter W, Bett AW. Localized irradiation effects on tunnel diode ransitions in multi-junction concentrator solar cells. 
Solar Energy Materials and Solar Cells 2009; 93(2209): 1692-1695.

8. Domínguez C. Antón I, Sala G. Solar simulator for concentrator photovoltaic systems. Optics Express 2008; 16(19): 14894-14901.

9. Leutz R, Suzukj A, Akisawa A, Kashiwagi T. Flux uniformity and spectral reproduction on solar concentrators using secondary optics. Proceedings of the ISES Solar World Congress. Kassel, Germany. 2001.

10. Victoria M, Domínguez C, Antón I, Sala G. Comparalive analysis of different secondary optical elements for aspheric primary lenses. Optics Express 2009; 17(8): 6487-6492.

11. Domínguez C. Askins S, Anton I. Sala G. Indoor characterization of CPV modules using the Helios 3198 solar simulator. Proceedings of the 24th European Photovoltaic Solar Energy Conference, Hamburg, Germany, 2009.

12. Antón I, Solar R. Sala G. Pachón D. $I-V$ testing of concentration modules and cells with non-uniform light pattems. Proceedings of the 17th European Photovoltaic Solar Energy Conference, Munich, Germany. 2001.

13. Rabl A. Active Solar Collectors and Their Applications, Oxford University Press: Oxford, 1985.

14. Herrero R. Victoria M. Askins S, et al Indoor characterization of multi-junction solar cells under non uniform light pattems. Proceedings of the 6th International Conference on Concentrating Photovoltaic Systems, Freiburg, Germany. 2010.
15. Andreev V. Grilikhes V, Rumyantsev V, Timoshina N, Shvarts M. Effect of nonuniform light intensity distribution on temperature coefficients of concentrator solar cell. Proceedings of the 3rd World Conference on Photovoltaic Energy Conversion. Osaka, Japan, 2003.

16. Algora C. Very-high-concentration challenges of III-V multijunction solar cells. In Concentrator Photovollaics, Luque A. Andreey V(eds). Springer: Berlin' Hejdelberg. 2007; 89-111.

17. Araki K. Kondo M. Uozumi H. Yamaguchi M. Experimental proof and theoretical analysis on effectiveness of passive homogenizers to $3 \mathrm{~J}$ concentrator solar cells. Proceedings of the 3rd World Conference on Photovoltaic Energy Conversion, Osaka, Japan. 2003.

18. James LW. Use of imaging refractive secondaries in photovoltaic concentrators. Contractor report SAND89-7029, Albuquerque. New Mexico. 1989.

19. McMahon WE. Emery KE, Friedman DJ. et al. Fill factor as a probe of current-malching for $\mathrm{GaInP}_{2} / \mathrm{GaAs}$ tandem cells in a concentrator system during outdoor operation. Progress in Photovoltaics: Research and Applications 2007; 16: 213-224.

20. Siefer G. Baur C. Meusel M, Dimroth F. Betl AW, Warta $W$. Influence of the simulator spectrum on the calibration of multi-junction solar cells under concentration. Conference Record of the 29th IEEE Photovoltaic Specialists Conference, New Orleans, LA, 2002. 